Noname manuscript No.

(will be inserted by the editor)

\title{
Electroplastic cutting influence on power consumption during drilling process
}

\author{
Saqib Hameed ${ }^{1}$ • Hernán A. González Rojas ${ }^{1, *}$ • \\ Antonio J. Sánchez Egea ${ }^{1}$ • Amelia Napoles \\ Alberro $^{2}$
}

Received: date / Accepted: date

\begin{abstract}
The aim of this study is to report the use of non-conventional material removal process technique. It was found that electropulses (EPs) assisted drilling process improves the material machinability based on the eletroplastic influence. The influence of EPs in drilling process is studied by combining different feed rates, drills diameters and current densities in 7075 aluminium and 1045 carbon steel. The results show that the electrically assisted drilling process improves material machinability, decreases the specific cutting energy up to $27 \%$ in aluminium and $17 \%$ in steel.
\end{abstract}

Keywords electropulse · drilling · cutting specific energy · power consumption · electroplasticity

\section{Introduction}

Drilling is one of the most commonly used material removal processes in manufacturing engineering. Significant progress has been achieved in drilling that resulted in improving the manufacturing quality of drills. Selecting the proper parameters such as speed and feed rate for a particular drilling operation is very important to reduce drill wear and breakage as well as to achieve high drilling efficiency. Speeds and feeds that are too high or too low, can reduce the efficiency of the whole operation. In drilling, optimum drill performance is achieved by selecting properly the cutting speed, feed, tool geometry and tool material depending upon workpiece material and quality requirements of drilled holes [1].

Energy saving is considered as one of the most important factors in manufacturing industry. Mori et al. [2] verified that in drilling process, the power consumption is decreased by increasing the feed rate and cutting speed within a value range which does not compromise the tool life. Mativenga et al. [3] presented that by selecting cutting conditions such as feed rate, cutting speed and depth of cut in turning process, the reduction in energy foot print is about $64 \%$ compared to using recommended cutting data from tool suppliers. Hae-Sung et al. [4] identified the energy

Saqib Hameed · Hernán A. González Rojas · Antonio J. Sánchez Egea

Department of Mechanical Engineering (EPSEVG), DEFAM group, Universitat Politécnica de Catalunya, Av. de Víctor Balaguer Vilanova i la Geltrú. 08800, Barcelona, Spain

E-mail: hameeds@tcd.ie; E-mail: hernan.gonzalez@upc.edu; E-mail: antonio.egea@upc.edu

Amelia Napoles Alberro

Department of Mechanical Engineering (EUETIB), DEFAM group, Universitat Politécnica de Catalunya, C/ Comte d'Urgell, 187. 08036, Barcelona, Spain

E-mail: amelia.napoles@upc.edu 
consumption and manufacturing cost behavior in terms of the process parameters in drilling. They found that fast machining process can reduce the energy consumption and only $35 \%$ of manufacturing cost can be saved.

In the drilling process, the elevated shear stress imposed by the cutting tool in the chip formation zone should exceed the strength of the work material. The distribution of these stresses must be such that the work material shows the strain at fracture as small as possible [5]. Geometrically, the surface is seen to have large number of minute irregularities (peaks and valleys) which cause residual stresses that influence the fatigue strength of critical parts besides causing harmful deformation. Therefore, surface quality is very important and its proper evaluation is of utmost interest as described by Astakhov [1]. Moreover, the main objective of machining is to separate a certain layer from the workpiece with minimum possible plastic deformation and thus energy consumption [5]. Therefore, energy spent on plastic deformation in drilling must be considered as wasted and high density EPs assisted drilling process is a novel technique that could solve this problem.

Electroplasticity has demonstrated that it can improve the mechanical properties of material. Hui et al. [6] showed that electoplasticity can increase the strength and maintains the required high ductility by increasing the elongation of material. The effect of EPs of high current density gives a significant decrease in yield stress [7]. The electrons exert a push on dislocations which is named as electron wind force. The electron wind force reduces the dislocation density and enhances the mobility of dislocation. In addition, high current density pulses also increase the mobility of atoms and reduce the strength of the obstacles opposing dislocation [8]. Zhang et al. [9] proved that cutting forces and hardness decreased and surface roughness improved in turning of specimens previously assisted by EPs of different frequencies. Recently, Sánchez et al. [10] stated that surface roughness can be improved while hardness decreased when the turning process is electrically assisted. Also they showed that the power consumption and the cutting specific energy were decreased with EPs. The EPs assisted drilling process intends to reduce power consumption and specific cutting energy compared to the conventional process due to low strain at fracture.

In this research, a new micropulse generator was designed and manufactured to assist the drilling process. High density EPs are induced in the cutting zone with minimum possible Joule effect of electroplasticity. The impact of EPs are analyzed on the power consumption, specific cutting energy and thermal stresses for different metallic materials. The ultimate objective is to study if differences are presented in the conventional drilling process when compared with the EPs assisted drilling process.

\section{Methodology}

An aeronautical aluminium alloy and a commercial steel alloy were chosen as workpiece materials for test samples. The specimens of aluminium alloy were cylindrical bars with a length of $20 \mathrm{~mm}$ and a diameter of $25 \mathrm{~mm}$. Where as the dimensions of steel alloy samples were $80 \mathrm{~mm}$ x $40 \mathrm{~mm} \mathrm{x}$ $15 \mathrm{~mm}$. The chemical composition of metallic materials is shown in Table 1.

Drilling process was carried out by using Huvema HU Profi Populair drilling. The tool was held by a standard tool holder. The cutting tool used was twist drill high speed steel (HSS) with point angle $116^{0}-120^{\circ}$ and helix angle $20^{\circ}-30^{\circ}$. The diameters of drill were $3 \mathrm{~mm}$ and $4.5 \mathrm{~mm}$. The polymer material was used to electrically isolate the workpiece and tool from drilling. 
Table 1 Material chemical composition.

\begin{tabular}{llllllllll}
\hline \multirow{2}{*}{7075 aluminium $\mathrm{T} 6$} & $\% \mathrm{Al}$ & $\% \mathrm{Zn}$ & $\% \mathrm{Mg}$ & $\% \mathrm{Cu}$ & $\% \mathrm{Fe}$ & $\% \mathrm{Si}$ & $\% \mathrm{Mn}$ & $\% \mathrm{Cr}$ & $\% \mathrm{Zr}$ \\
& 87.2 & 6.1 & 2.9 & 2.0 & 0.5 & 0.4 & 0.3 & 0.28 & 0.25 \\
\hline \hline \multirow{2}{*}{1045 carbon steel } & $\% \mathrm{C}$ & $\% \mathrm{Ni}$ & $\% \mathrm{Mo}$ & $\% \mathrm{Cu}$ & $\% \mathrm{~S}$ & $\% \mathrm{Si}$ & $\% \mathrm{Mn}$ & $\% \mathrm{Cr}$ & $\% \mathrm{P}$ \\
& 0.45 & 0.17 & 0.05 & 0.35 & 0.035 & 0.26 & 0.60 & 0.10 & 0.02 \\
\hline
\end{tabular}

In drilling, the parameters used are spindle speed of $1050 \mathrm{rpm}$ and a range of feed velocity of 0.2 to $0.4 \mathrm{~mm} / \mathrm{s}$. The nominal power consumption was continuously measured by a self made monophasic energy analyzer linked to the motor of the machine. The sampling rate was analogic with storage after every $0.5 \mathrm{~s}$. A self made short duration electric pulse generator was manufactured to discharge multiple positive pulses. The parameters of current pulses such as voltage, frequency and pulse duration were monitored and controlled by an oscilloscope. The parameters of current used are listed in Table 2.

Table 2 Electropulsing operation parameters.

\begin{tabular}{lllll}
\hline Material & $\begin{array}{l}\text { Current intensity } \\
(\mathrm{A})\end{array}$ & $\begin{array}{l}\text { Pulse duration } \\
(\mu \mathrm{s})\end{array}$ & $\begin{array}{l}\text { Frequency } \\
(\mathrm{Hz})\end{array}$ & $\begin{array}{l}\text { Average output power } \\
(\text { Watts })\end{array}$ \\
\hline \hline 7075 Al. & 140 & 250 & 300 & 300 \\
1045 Steel & 250 & 300 \\
\hline
\end{tabular}

A schematic illustration of electrically assisted drilling process is shown in Figure 1.

The workpieces were cut facing process to make sure the surface was smooth. The carbon clamps were attached on one side with round smooth element in the tool holder and on other side connected with generator through wire. The workpiece was also connected with generator through wire. Then, drilling operation was performed without EPs (conventional process). Subsequently, the same procedure was performed but assisted with EPs. The EPs were induced when the drill was already in contact with the material, in order to avoid sparking (electroerosion). Later, the power consumption and specific cutting energy of both processes have been compared. Finally, the removal chip was thoroughly polished and prepared to measured the chip thickness with an optical microscope.

\section{Results and Discussions}

\subsection{Current density and cutting configuration}

In a material removal process the large strains are imparted to the chip at the primary deformation zone [11]. For this reason it is necessary to estimate the current density induced in this zone. The current density is defined as current intensity which goes through the cross sectional area of the material. Here it is assumed that the current flows through the tool-chip contact length and then goes across the shear cutting area, making a close electric circuit with the workpiece. The shear cutting area is defined by the segment $\mathrm{OA}$ and the length of the cutting edge $b$, as shown in Figure 2 .

The nominal chip thickness or undeformed chip thickness $a$ can be estimated as: 


\section{Power data acquisition}

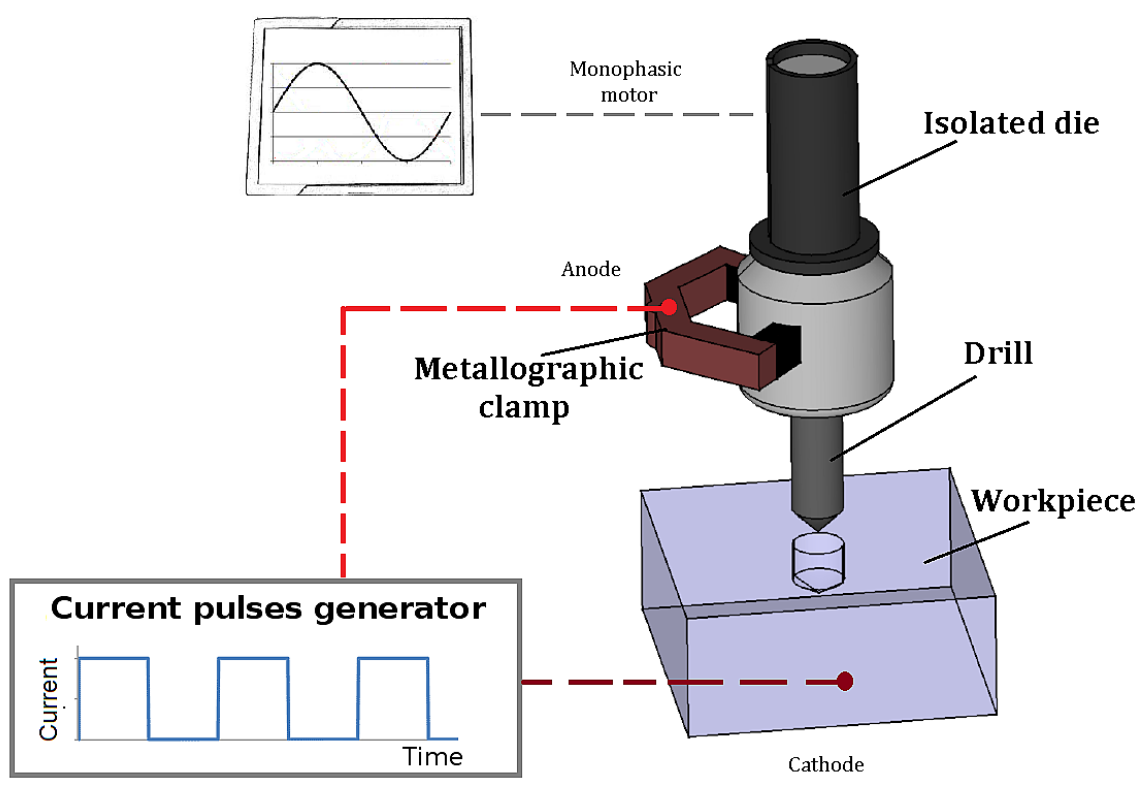

Fig. 1 Schematic of electrically assisted drilling process.

$$
a=\frac{f}{2} \cdot \sin \left(\frac{\varphi}{2}\right)
$$

where $f$ is the feed rate ( $\mathrm{mm}$ per second), $\varphi$ is the point angle $\left(^{\circ}\right)$.

Additionally, the segment OA is described by:

$$
O A=\frac{a}{\sin (\phi)}
$$

where $\phi$ is the shear plane angle $\left(^{\circ}\right)$.

Then, the nominal cutting width is defined by:

$$
b=\frac{\frac{0.85 \cdot d_{r}}{2}}{\sin \left(\frac{\phi}{2}\right)},
$$

where $d_{r}$ is drill diameter $(\mathrm{mm})$.

Consider the shear angle plane of drill bit to estimate the current density $J_{e}$ at cutting edge of drill. Therefore, the current density can be calculated by the following equation

$$
J_{e}=\frac{2 \cdot I \cdot \sin (\phi)}{0.8 \cdot f \cdot d_{r}},
$$

where $I$ is the current intensity (A).

The shear plane angle $\phi$ proposed in [12] can be expressed geometrically by chip compression ratio $\xi$ as 


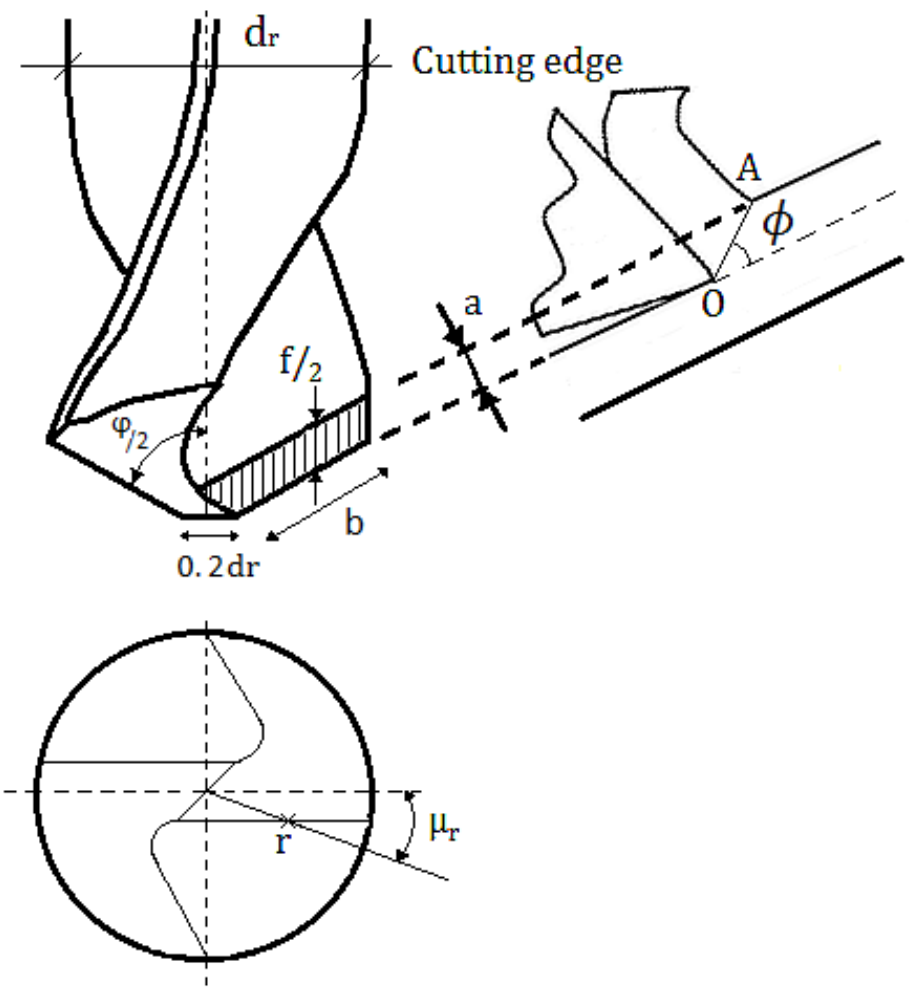

Fig. 2 Graphical model for the determination of uncut chip thickness.

$$
\phi=\arctan \left(\frac{\cos \alpha}{\xi-\sin \alpha}\right)
$$

Chip thickness coefficient defines as a ratio $\xi=a_{1} / a$, where $a_{1}$ is deformed chip thickness. $\alpha$ is the rake angle which is also helix angle in drilling. The value of helix angle for drills under study is $30^{\circ}$.

The chip removed by the drilling tool was encapsulated in resin. A conventional polishing process was conducted until revealed the cross sectional area presented in Figure 3a. The average chip thickness was measured by capturing the images with an optical microscope to calculate the area and the length of the chip in pixel and then convert into $\mathrm{mm}$ with a calliper. The average chip thickness is defined as the quotient between the cross sectional area of the chip and the chip length. Each value of chip thickness is the average of ten measurements and the margin error is up to $8 \%$ of a standard deviation estimation. The Figure $3 \mathrm{~b}$ exhibits the zoom of the cross section of chip used to calculate the chip thickness experimentally. 
a



Fig. 3 (a) Cross sectional area of chip. (b) Zoom of a single chip segment.

The drill used during the experiments has not automatic feed rate configuration, therefore it was necessary to estimate the feed velocity and the spindle velocity to be able to calculate the feed rate $f$. An optical $\mathrm{ON} / \mathrm{OFF}$ switch control with a timer was used to measure the feed velocity. A metallic strip attached to the axle of the drill was used to change the switch status. Subsequently, the feed velocity was defined by the strip length and the time registered with the timer. The spindle velocity in rpm was measured with a conventional tachometer. Table 3 gives the values of chip compression ratio, shear plane angle and current density as a function of feed rate in drilling for 1045 carbon steel and 7075 aluminium.

Table 3 Values of chip compression ratio, shear plane angle and current densities as functions of feed rates.

\begin{tabular}{|c|c|c|c|c|c|c|}
\hline Material & $\begin{array}{l}\text { Drill } \\
\text { diameter } \\
\left(d_{r}\right) \\
{[\mathrm{mm}]}\end{array}$ & $\begin{array}{l}\text { Feed rates } \\
(\mathrm{f}) \\
{[\mu \mathrm{m} / \mathrm{rev}]}\end{array}$ & $\begin{array}{l}\text { Undeformed chip } \\
\text { thickness } \\
(\mathrm{a}) \\
{[\mu \mathrm{m}]}\end{array}$ & $\begin{array}{l}\text { Chip compression } \\
\text { ratio } \\
(\xi)\end{array}$ & $\begin{array}{l}\text { Shear plane } \\
\text { angle } \\
(\phi) \\
{\left[^{\circ}\right]}\end{array}$ & $\begin{array}{l}\text { Current } \\
\text { density } \\
\left(J_{e}\right) \\
{\left[A / \mathrm{mm}^{2}\right.}\end{array}$ \\
\hline \multirow{2}{*}{7075 Al. } & 3 & 97.71 & 41.52 & 3.37 & 16.79 & 354 \\
\hline & 4.5 & 18.68 & 7.93 & 5.33 & 10.15 & 758 \\
\hline \multirow{2}{*}{1045 Steel } & 3 & 48.17 & 20.47 & 4.37 & 12.61 & 544 \\
\hline & 4.5 & 51 & 21.67 & 4.53 & 12.12 & 329 \\
\hline
\end{tabular}

It can be noticed that the shear angle $\phi$ decreases as the chip compression ratio $\xi$ increases. Also the chip compression ratio $\xi$ decreases with the increase of feed rate. The chip compression ratio $\xi$ can be considered as a measure of plastic deformation of material [4]. The high values of chip compression ratio (low $\phi$ values) mean large amount of strain in the shear plane [13]. So the values of chip compression ratio and shear plane angle give an intensive amount of plastic deformation at the shear zone. The current density increases with the decrease of feed rates during electrical assisted drilling process as shown in Table 3. The effect of these densities is presented in the section of thermal expansion to calculate the adiabatic temperature rise and thermal stresses in the materials.

\subsection{Thermal expansion}

The high rise of temperature described by Joule heating effect is calculated to determine the contribution of factor in the electrically assisted drilling process. Okazaki et al. [14] observed that the thermal effect of electropulsing can reduce the deformation resistance and improve the plasticity of material. They described the adiabatic temperature, $\Delta T$ for a single EP by the following equation; 


$$
\Delta T=\frac{J_{e}^{2} \cdot \rho \cdot t_{p} \cdot f}{C_{p} \cdot D}
$$

where $J_{e}$ is the effective current density, also called root mean square value of current density, $\rho$ is the resistivity, $t_{p}$ is the EP duration, $f$ is the frequency discharge, $C_{p}$ is the specific heat and $D$ is the density of materials.

Table 4 Properties of materials.

\begin{tabular}{llllll}
\hline \multirow{2}{*}{ Material } & $\begin{array}{l}\rho \\
(\Omega m)\end{array}$ & $\begin{array}{l}C_{p} \\
\left(\mathrm{~J} / \mathrm{Kg}^{\circ} \mathrm{C}\right)\end{array}$ & $\begin{array}{l}E \\
(\mathrm{GPa})\end{array}$ & $\begin{array}{l}\alpha \\
\left({ }^{\circ} \mathrm{C}^{-1}\right)\end{array}$ & $\begin{array}{l}\mathrm{D} \\
\left(\mathrm{Kg} / \mathrm{m}^{3}\right)\end{array}$ \\
\hline \hline 7075 Al. & $5.15 \times 10^{-8}$ & 960 & 71.7 & $21.6 \times 10^{-6}$ & 2810 \\
\hline 1045 Steel & $1.62 \times 10^{-7}$ & 486 & 206 & $11.5 \times 10^{-6}$ & 7850 \\
\hline
\end{tabular}

To calculate the adiabatic rise in temperature, the properties of materials are shown in Table 4. An adequate thermal effect resulting from the Joule heating effect of electroplastic treatment is necessary to increase the nucleation rate of recrystallization [15]. The exact mechanism of athermal effect is still not very clear; however there is possibility that it results from additional force of electrons exert on a dislocation called electron wind, the Joule heating effect and thermal stresses. Due to very short duration, the tremendous force should be impacted which further enhances irregular speed of atoms based on thermal effect. As the force increases the superior athermal effects will be produced due to higher values of electron current density [16]. The defects such as micro-crack, cavity and void can be produced in machining processes. Because of these defects, the resistivity is higher in the area with defects than that without defects. When the EPs are passed through the metal specimen, the temperature rise is higher in the area with defects than that without defects due to inhomogeneous resistivity in the metal. This inhomogeneous rise of temperature causes inhomogeneous thermal expansion and the defected area suffers compressive stresses as compared to area without defects [9].

Then, based on the high-rate heating of EPs, the maximum thermal stress suggested by Tang et al. [17] can be written as:

$$
\sigma_{\max }=E \cdot \alpha \cdot \Delta T
$$

where $E$ is Young's modulus and $\alpha$ is the coefficient of thermal expansion.

Table 5 Adiabatic temperature and thermal stress values.

\begin{tabular}{llll}
\hline Material & $\begin{array}{l}\text { Drill diameter } \\
(\mathrm{mm})\end{array}$ & $\begin{array}{l}\Delta T \\
\left({ }^{\circ} \mathrm{C}\right)\end{array}$ & $\begin{array}{l}\sigma_{\max } \\
(\mathrm{GPa})\end{array}$ \\
\hline \hline \multirow{2}{*}{$7075 \mathrm{Al}}$. & 3 & 179 & 0.28 \\
& 4.5 & 823 & 1.27 \\
\hline \multirow{2}{*}{1045 Steel } & 3 & 942 & 2.23 \\
& 4.5 & 345 & 0.82 \\
\hline
\end{tabular}


When the current pulses of short duration passed through the specimen, the Joule heating effect occurred in the specimen. Due to very short duration of EPs, the material particles undergo heavy stress impact [18]. Because of the increase of current density, a higher rise in temperature would be produced and hence the maximum stresses will be increased during EPs treatment, as shown in Table 5. So maximum stresses would be induced by increasing the current density, which is strong enough to accelerate the motion of dislocations. Accordingly, nucleation rate of recrystallization can be increased by advancing the mobility of dislocations during electropulsing treatment [19]. Hence, electrically assisted processes play a vital role in the enhancement of mechanical properties of materials.

\subsection{Power consumption}

The electric energy consumption by the machine is proportional to the cutting force required to initiate the chip removal. Stephenson et al. [11] defined that the specific cutting power also called specific cutting energy (SCE) is the amount of energy spent to cut per volume of the work material per unit time. It is often used to compare the machinability of different materials, especially when relative tool life data are unavailable. Ekincioglu et al. [20] stated that efficient cutting process requires maximum cutting speed and minimum SCE. Therefore, the SCE becomes a measure of cutting efficiency and a criterion as well. The SCE is the sum of the energy consumed in the primary, secondary and tertiary deformation zones [21].

The power consumption during the cutting process was measured by self made energy analyzer. The net active power $W_{n}$ is determined by taking the difference between the average power when the cutting tool is removing the material and the power when machine is idle. In this section, the net power obtained in a conventional drilling process is compared with a power obtained in electrically assisted drilling process. The hypothesis is: the net power consumed in assisted drilling process is less than the power consumed by conventional drilling process.

Figure 4 shows the experiments performed to calculate SCE with pulse duration of $250 \mu \mathrm{s}$, frequency of $300 \mathrm{~Hz}$ and drill diameters of $3 \mathrm{~mm}$ and $4.5 \mathrm{~mm}$ for 7075 aluminium and 1045 carbon steel. The SCE values shown are the average of ten measurements registered in each case during assisted and conventional drilling operations. The margin errors represent the t-student distribution with a $95 \%$ confidence interval.

In Figure 4 the application of EPs has been observed to reduce the SCE in drilling process. The maximum reduction of SCE was observed $2.064 \mathrm{~W} . \mathrm{s} / \mathrm{mm}^{3}$ for 7075 aluminium and the least was observed $0.435 \mathrm{~W} . \mathrm{s} / \mathrm{mm}^{3}$ for 1045 steel with $3 \mathrm{~mm}$ drill diameter, $250 \mu$ s pulses and $300 \mathrm{~Hz}$ frequency. The use of pulses with high frequency and large duration values shows a large reduction of SCE. For these cases, the average reduction of SCE was about $0.716 \mathrm{~W} . \mathrm{s} / \mathrm{mm}^{3}$. These results show an improvement of the material machinability when drilling process is assisted with EPs compare with respect to the conventional drilling process.

Sood et al. [22] stated that specific cutting energy can be calculated as quotient of the net energy and material removal rate. The material removal rate $Q_{c}$ is the volume of material removed per unit time. In this particular case, it is estimated by a feed velocity which crosses perpendicularly to the section of the material removed by the drill. Therefore, the $Q_{c}$ (measured in $\mathrm{mm}^{3} / \mathrm{s}$ ) is a function of cutting conditions and can be written as:

$$
Q_{c}=\frac{\pi \cdot d_{d r}^{2}}{4} \cdot V_{f}
$$


$\mathbf{a}$

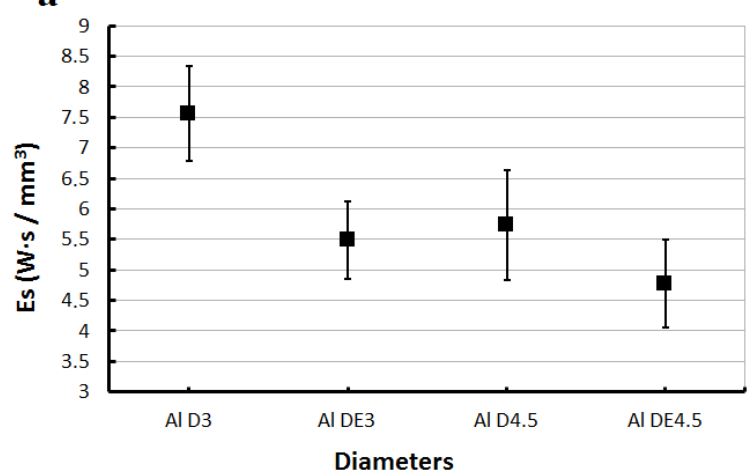

b

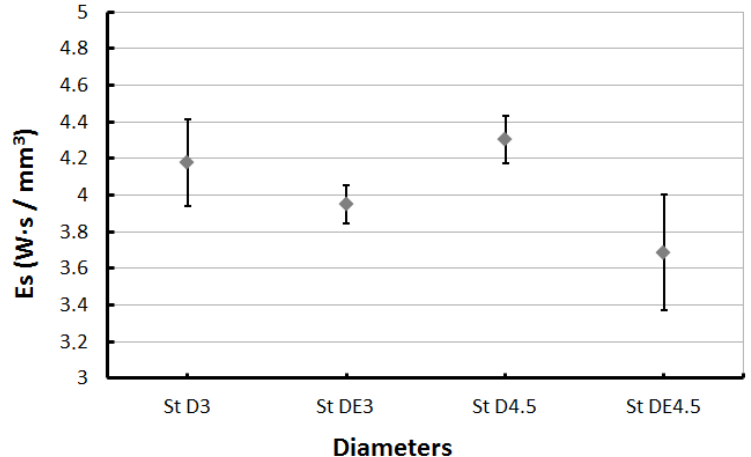

Fig. 4 Cutting specific energy for 7075 aluminium (a) and 1045 carbon steel (b).

where $V_{f}$ is feed velocity $(\mathrm{mm} / \mathrm{s})$ and $d_{d r}$ is the drill diameter.

Then, the SCE is the energy consumed per unit of volume of the material removed and can be described as,

$$
E_{s}=\frac{N_{c}}{Q_{c}},
$$

where $N_{c}(\mathrm{~W})$ is the effective cutting power consumed during drilling.

To compare the assisted process with the conventional process the percentage of reduction $r_{p}$ in the SCE is evaluated. This reduction is defined as:

$$
r_{p}=1-\frac{E_{s}(\text { assisted })}{E_{s}(\text { conventional })},
$$

where $E_{s}$ is the SPE.

In Table 6, the percentage of SCE reduction values are presented for 7075 aluminium and 1045 steel, calculated from equation (10) for drill diameters of $3 \mathrm{~mm}$ and $4.5 \mathrm{~mm}, 300 \mathrm{~Hz}$ frequency and $250 \mu$ s pulse duration.

Table 6 Specific cutting energy percentage reduction

\begin{tabular}{lllll}
\hline $\begin{array}{l}d_{r} \\
(\mathrm{~mm})\end{array}$ & $\begin{array}{l}\text { Frequency } \\
(\mathrm{Hz})\end{array}$ & $\begin{array}{l}\text { Duration } \\
(\mu \mathrm{s})\end{array}$ & $\begin{array}{l}7075 \mathrm{Al} . \\
\left(\% r_{p}\right)\end{array}$ & $\begin{array}{l}1045 \text { Steel } \\
\left(\% r_{p}\right)\end{array}$ \\
\hline \hline 3 & \multirow{2}{*}{300} & \multirow{2}{*}{250} & 27.3 & 9.9 \\
4.5 & & 16.7 & 16.6 \\
\hline
\end{tabular}

The 7075 aluminium registered a reduction of approximately $27.3 \%$ and $16.7 \%$ and 1045 carbon steel showed about $9.9 \%$ and $16.6 \%$ with drill diameters of $3 \mathrm{~mm}$ and $4.5 \mathrm{~mm}$ respectively during EPs treatment. These results concluded that it is not necessary that small diameters could achieve higher reduction in SCE. It seems to depend on the type of material. However, the results are 
similar with those presented by Zhang et al. [7], where the maximum decrease in specific energy was $54 \%$ in rolling process of high frequency current pulses. Recentally, Sánchez et al. [8] proved that the 4140 carbon steel presented a reduction of SCE of approximately $25 \%$ for EPs of $300 \mathrm{~Hz}$ frequency and $200 \mu \mathrm{s}$ in turning process.

\section{Conclusions}

Electrically assisted drilling process has been proved to be a feasible technique which improves the material machinability compared with the conventional drilling process.

There is a correlation between chip compression ratio $\xi$, shear angle $\phi$, feed rates and current density in EPs assisted drilling process. When lower feed rates are used and subsequently higher current density values are induced the shear angle decreases and the chip compression ratio increases.

The cutting specific energy is reduced up to $27 \%$ in 7075 aluminium and $17 \%$ in 1045 steel when the drilling process is assisted with EPs. The electrically assisted drilling process seems to have influence on improving the material machinability, but further investigations need to be done with different EPs configurations to determine the trends and contributions of each electrical parameter.

\section{Acknowledgements}

The authors are very grateful to the Departament d'Enginyeria Mecánica, Universitat Politècnica de Catalunya by the financial support through the grant Projectes de reserca del DEM-2015. The authors have no other professional and/or financial affiliations that may have biased the article.

\section{References}

1. Astakhov VP (2014) Drills: Sci Technol Adv Operations. CRC Press, Taylor and Francis Group

2. Mori M, Fujishima M, Inamasu Y, Oda Y (2011) A study on energy efficiency improvement for machine tools. CIRP Annals - Manufac Technol 60:145-148

3. Mativenga PT, Rajemi MF (2011) Calculation of optimum cutting parameters based on minimum energy footprint. CIRP Annals - Manuf Technol 60:149-152

4. Yoon HS, Moon JS, Pham MQ, Lee GB, Ahn SH (2013) Control of machining parameters for energy and cost savings in micro-scale drilling of PCBs. J Clean Prod 54:41-48

5. Astakhov VP, Shvets S (2004) The assessment of plastic deformation in metal cutting. J Mater Process Technol 146:193-202

6. Hui S, Zhong JW (2012) Improvement of mechanical properties of cold-rolled commercially pure Ti sheet by high density electro-pulsing. Trans Nonferrous Metals Soc China 22:1350-1355

7. Hui S, Zhong JW, Tie JG (2007) Effect of high density electro-pulsing treatment on formability of TC4 titanium alloy sheet.Trans Nonferrous Metals Soc China 17:87-92

8. Hui S, Zhong JW (2011) Grain refinement by means of phase transformation and recrystallization induced by electro-pulsing. Trans Nonferrous Metals Soc China 21:s353-s357

9. Zhang D, To S, Zhu YH, Wang H, Tang GY (2012) Static Electro-pulsing Induced Microstructural Changes and Their Effect on the Ultra-Precision Machining of Cold-Rolled AZ91 Alloy. Metallurgical Mater Trans A 43A:1341-1346

10. Sánchez AJ, González HA, Montilla CA, Echeverri VK (2015) Effect of electroplastic cutting on the manufacturing process and surface properties. J Mater Process Technol 222:327-334

11. Stephenson DA, Agapiou JS (2005) Metal Cutting Theory and Practice. CRC Press sec ed Taylor and Francis Group.

12. Feng K, Jun N, Stephenson DA (2006) Chip thickening in deep-hole drilling. Int J Mach Tools Manuf 46:15001507 
13. Silva LR, Abrao AM, Faria P, Davim JP (2012) Machinability study of steels in precision orthogonal cutting. Mater Research 15(4):589-595

14. Okazaki K, Kagawa M, Conrad H (1980) An evaluation of the contributions of skin, pinch and heating effects to the electroplastic effect in titanium. Mater Sci Eng 45:109-116

15. Tang G, Zhang J, Yan Y, Zhou H, Fang W (2003) The engineering application of the electro-plastic effect in the cold-drawing of stainless steel wire. J Mater Technol 137:96-99

16. Xu Z, Tang G, Tian S, Ding F, Tian H (2007) Research of electro-plastic rolling of AZ31 Mg alloy strip. J Mater Process Technol 182:128-133

17. Tang DW, Zhou BL, Cao H, He GH (2003) Thermal-stress relaxation behavior in thin-films under transient laser-pulse heating. J Appl Physics 73:3749-3752.

18. Zhang W, Sui ML, Zhou YZ, Li DX (2003) Evolution of microstructures in materials induced by electropulsing. Micron 34:189-198

19. Du XN, Yin SM, Liu SC, Wang BQ (2008) Effect of the electropulsing on mechanical properties and microstructure of an ECAPed AZ31 Mg alloy. J Mater Research 23(06):1570-1577

20. Ekincioglu G, Altindag R, Sengun N, Demirdag S, Guney A (2013) The relationships between drilling rate index (DRI), physico-mechanical properties and specific cutting energy for some carbonate rocks. Rock Mech Resources Energy Env 136:867-873

21. Boothroyd G, Knight WA (1989) Fundamentals of Metal Machining and Machine Tools. Mercel Dekker, second ed., New York.

22. Sood R, Guo C, Malkin S (2000) Turning of hardened steels. J Manuf Process 2(03):187-193 